\title{
Acute stroke due to air embolism complicating
} ERCP

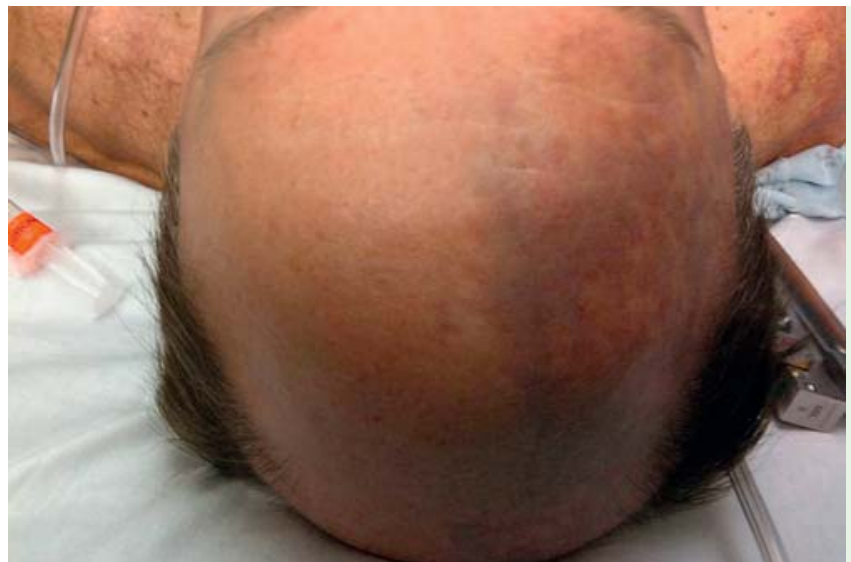

Fig. 1 Forehead skin discoloration.

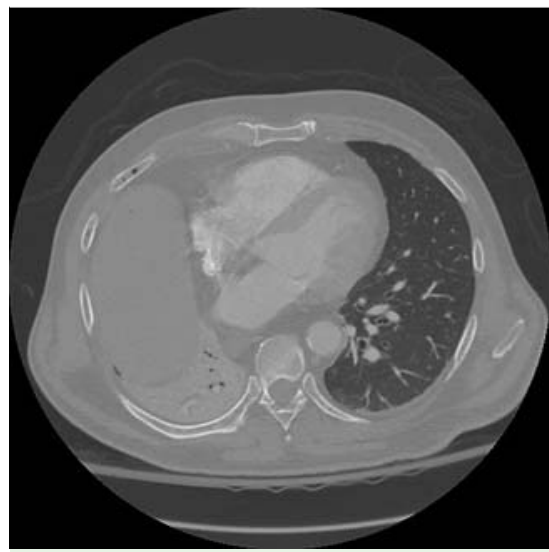

Fig. 2 Computed tomographic angiography shows air in the pulmonary artery branches.

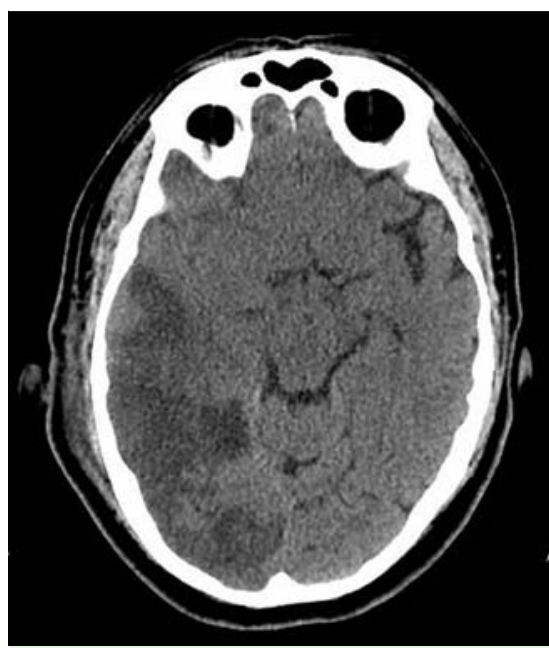

Fig. 3 Head computed tomography shows air in the cerebral artery system.

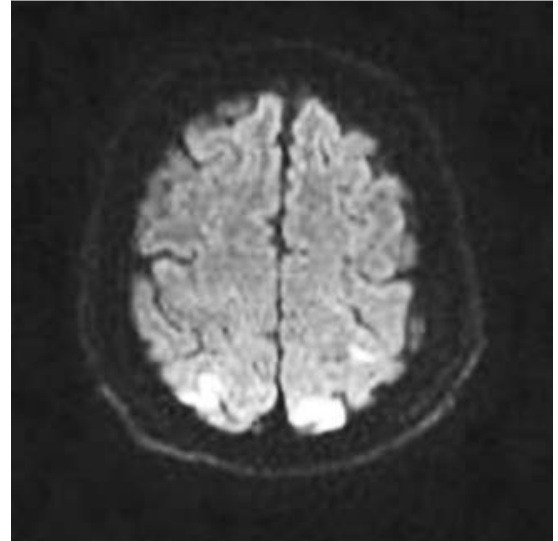

Fig. 4 Magnetic resonance imaging (MRI) of the brain shows embolic infarctions of the bilateral posterior parietal lobes.

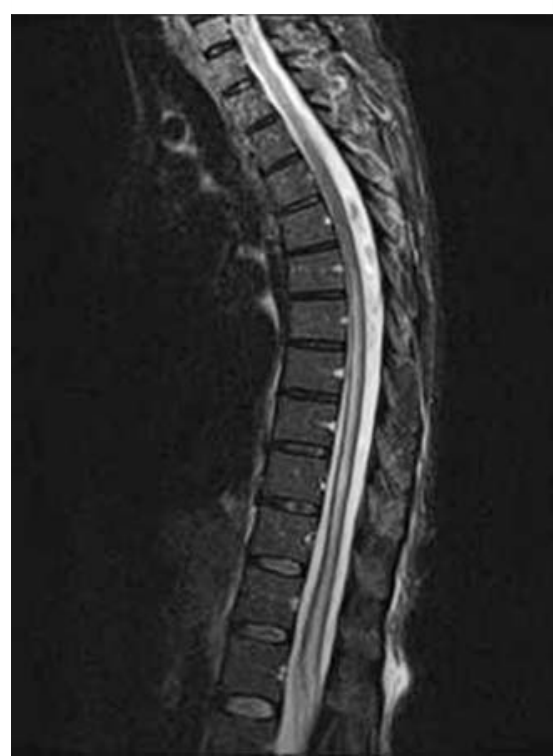

Fig. 5 Spine MRI (sagittal view) shows spinal cord infarction from T6 through to the conus.

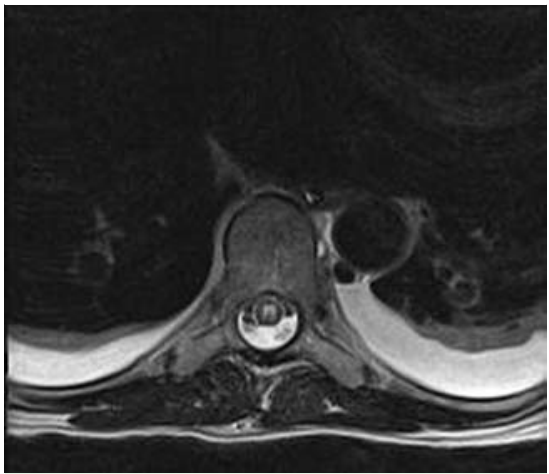

Fig. 6 Spine MRI (axial view) shows spinal cord infarction.

Air embolism is a rare, but severe complication of endoscopic retrograde cholangiopancreatography (ERCP). We present two cases of acute stroke after ERCP due to intracranial and spinal air embolism. Our second case is the first report of spinal cord air embolism.

A 66-year-old man with bile duct stricture presented for biliary stent exchange. Oxygen desaturation, ocular deviation, and forehead skin discoloration ( $\bullet$ Fig. $\mathbf{1}$ ) were noted on change of the patient position from prone to supine. A transthoracic echocardiogram (TTE) revealed left-sided intracardiac air and a patent foramen ovale. The patient was treated with hyperbaric oxygen. Computed tomographic angiography revealed air in the pulmonary artery branches ( $\boldsymbol{\Theta}$ Fig. $\mathbf{2}$ ) and head computed tomography showed air in the cerebral arterial system ( $\mathbf{F i g . 3}$ ). The patient died after experiencing severe cerebral injury.

A 51-year-old woman status post Whipple's operation underwent ERCP for evaluation of recurrent attacks of pancreatitis. Ocular deviation and paraplegia were noted. Magnetic resonance imaging revealed multiple embolic infarctions of the bilateral posterior parietal lobes ( $\bullet$ Fig. 4 ) and extensive spinal cord infarction from T6 through the conus ( $\bullet$ Fig.5, $\bullet$ Fig. $\mathbf{6}$ ). A TTE revealed intra-atrial shunt. The patient was treated with supportive measures. She had complete resolution of the upper extremity weakness, but some residual lower extremity deficits remained. Air embolism at the time of ERCP can cause cardiovascular, pulmonary, and neurologi- 
cal symptoms [1,2]. Symptom onset during the position change from prone to supine is characteristic and should trigger immediate suspicion for air embolism. Potentially lifesaving therapeutic measures should be promptly initiated, including placing the patient in Trendelenburg and left lateral decubitus position, high-flow oxygen, and volume expansion. Arrangements for urgent hyperbaric oxygenation therapy should be made. Air aspiration via central venous catheter should be considered if right heart air is noted.

Endoscopy_UCTN_Code_CPL_1AK_2AI

Competing interests: None

\section{Chavalitdhamrong, P. V. Draganov}

University of Florida, Gainesville, Florida, USA

\section{References}

1 Sviri S, Woods WP, van Heerden PV. Air embolism - a case series and review. Crit Care Resusc 2004; 6: 271-276

2 Mirski MA, Lele AV, Fitzsimmons L et al. Diagnosis and treatment of vascular air embolism. Anesthesiology 2007; 106: 164-177

\section{Bibliography}

Dol http://dx.doi.org/

10.1055/s-0032-1326643

Endoscopy 2013; 45: E177-E178

(c) Georg Thieme Verlag KG

Stuttgart · New York

ISSN 0013-726X

\section{Corresponding author}

\section{P. V. Draganov, MD}

University of Florida, Room HD 602

PO Box 100214

Gainesville

FL 32610

USA

Fax: +1-352-392-3618

dragapv@medicine.ufl.edu 